\title{
Multistep approach for control of postpartum hemorrhage in placenta accreta: a novel scheme in a tertiary referral center
}

\author{
Ahmed Samy El-Agwany*, Tamer Mamdouh Abdeldayem
}

Department of Obstetrics and Gynaecology, El-shatby maternity hospital, Alexandria University, Alexandria, Egypt

Received: 22 June 2016

Accepted: 12 July 2016

\section{*Correspondence:}

Dr. Ahmed elagwany,

E-mail: ahmedsamyagwany@gmail.com

Copyright: ( $)$ the author(s), publisher and licensee Medip Academy. This is an open-access article distributed under the terms of the Creative Commons Attribution Non-Commercial License, which permits unrestricted non-commercial use, distribution, and reproduction in any medium, provided the original work is properly cited.

\section{ABSTRACT}

Background: Placenta accreta is a major cause for massive postpartum hemorrhage and consequent obstetric hysterectomy. Incidence is rising secondary to increased rates of caesarian delivery worldwide.

Methods: From January 2014 to January 2016, 25 women with anterior low-lying placenta and previous caesarian section(s) were recruited at El-Shatby Maternity university hospital in Alexandria, Egypt. Cases had previous 1-4 lower segment caesarian deliveries. Cases were diagnosed as placenta accreta by ultrasonographic examination on admission to hospital. Elective surgery was done at 36-37 weeks. Mid line abdominal incision with upper segment uterine incision with plication of lowers uterine segment with transverse compression sutures.

Results: We present a clinical trial for conservative management of placenta accreta in 25 cases with 19 cases [76\%] successfully managed without hysterectomy.

Conclusions: Conservative management of placenta accreta can be successfully performed in young age females desiring fertility.

Keywords: Placenta, Accreta, Hysterectomy, Ultrasound, Hemorrhage

\section{INTRODUCTION}

Postpartum haemorrhage (PPH) is a leading cause of maternal mortality worldwide and is responsible for approximately $25 \%$ of all maternal deaths. Placental abnormalities are a major contributor to obstetric haemorrhage. The most common placental abnormalities are placental abruption, placenta previa, and an adherent (accrete, increta, or percreta). ${ }^{1}$ Placenta accreta is one of the most serious complications of anterior placenta previa with previous lower segment caesarian delivery. Invasion of the placental tissue into the myometrium occurs with varying degree, resulting in deficient contraction of lower uterine segment and haemostasis at the placental bed. It is associated with severe obstetric haemorrhage usually necessitating hysterectomy. ${ }^{2}$

Several methods were proposed for control of haemorrhage, with no gold standard method agreed upon yet in literature.
Aim of the study was to evaluate the efficacy of lower segment plication and compression sutures at the placental bed to control bleeding in cases of placenta accreta avoiding hysterectomy.

\section{METHODS}

From January 2014 to January 2016, 25 women with anterior low-lying placenta and previous caesarian section(s) were recruited at El-Shatby Maternity university hospital in Alexandria, Egypt. This hospital is a tertiary center for 3 governorates in Egypt with population exceeding 10 million and caesarian section rate approaching $40 \%$ of all deliveries. This study was approved by the Ethics Committee of the hospital and a written informed consent form was signed by the women and/or their nearest relatives before the operation. Cases had previous 1-4 lower segment caesarian deliveries. Cases were diagnosed as placenta accreta by ultrasonographic examination on admission to hospital. Criteria for ultrasonographic diagnosis were: ${ }^{3}$ 
1. Location of placenta: anterior placenta previa

2. Loss of retro placental clear space

3. Irregularity of uterine bladder interface: caused by abnormal bridging vasculature that is easily seen with Doppler ultrasound

4. Thinning of uterine bladder interface. The smallest myometrial thickness in sagittal plane $<1 \mathrm{~mm}$

5. Placenta lacunar spaces: spaces are graded according to Finberg and Williams as follows:

- Grade 0: no lacunar spaces are seen

- Grade 1:1-3 lacunar spaces present and generally small

- Grade 2: 4-6 lacunar spaces present and tending to be larger and more irregular

- Grade 3: many lacunar spaces throughout the placenta and appearing large and bizarre.

6. Placental bulge: deviation of the uterine serosa away from the expected plane

7. Focal exophytic mass

8. Bridging vessels: Doppler colored mapping demonstrates abnormal vasculature that bridge from placental mass to uterine bladder interface

9. Utero-vesicle hyper vascularity

10. Sub-placental hyper vascularity

11. Placental lacunae feeder vessels.

Cases underwent elective caesarian delivery at 36-37 weeks gestation with the following steps (Figure 1-3):

- Right infraumbilical para median abdominal incision was done

- Dissection of the bladder flap down to cervical canal was done prior to uterine incision, to reduce time needed for lower segment plication after extraction of the placenta

- Longitudinal incision was used in the uterus to avoid cutting through the anterior low-lying placenta, and fetus was extracted

- Preventive measures were done to avoid upper segment atony; in the form of: warm towels, uterotonics agents (oxytocin, carbetocin, ergometrin and/or prostaglandin analogs)

- Bilateral uterine artery ligation prior to placental removal, to decrease the pulse pressure in placental bed and subsequent bleeding

- After removal of the placenta, Vicryl number 1 absorbable thread (Ethicon Inc., Somerville, NJ,USA) on a 70-mm round needle was used for plication of lower uterine segment .

- Multiple transverse compression sutures connecting anterior wall of lower uterine segment to the posterior one were applied, with preservation of a canal in the middle of the cavity for drainage of blood. A suture was started from anterior to posterior wall, just above the internal cervical os, then from the posterior to the anterior one was done.
- Repair of upper segment incision was then done with Vicryl 1 thread and and $40 \mathrm{~mm}$ needle.

- Blood and fresh plasma transfusion was concurrently done, with plasma expanding crystalloids.

Cases that failed to achieve adequate hemostasis and progressed to life threatening hemorrhage proceeded to obstetric hysterectomy with ovarian preservation.

\section{RESULTS}

Of the studied 25 cases, 19 had successful conservative treatment, 6 had obstetric hysterectomy (Table 1).

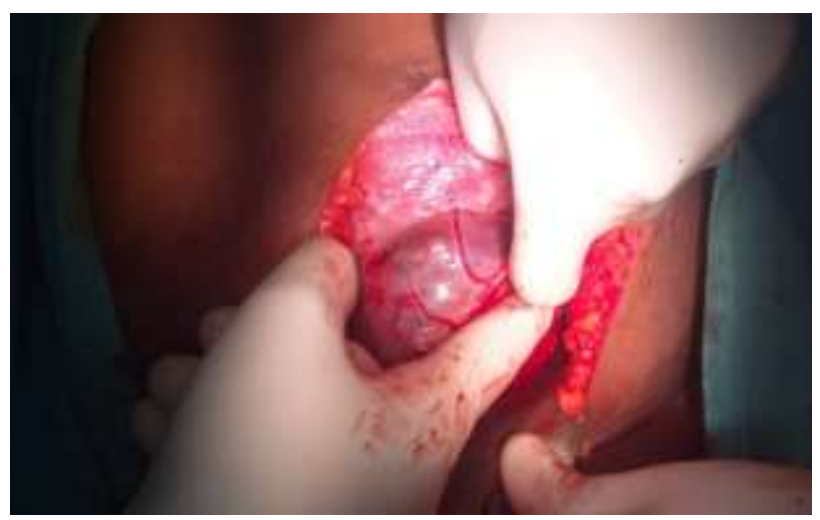

Figure 1: Right para-midline incision revealing placenta invading the myometrium and reaching to the serosa.

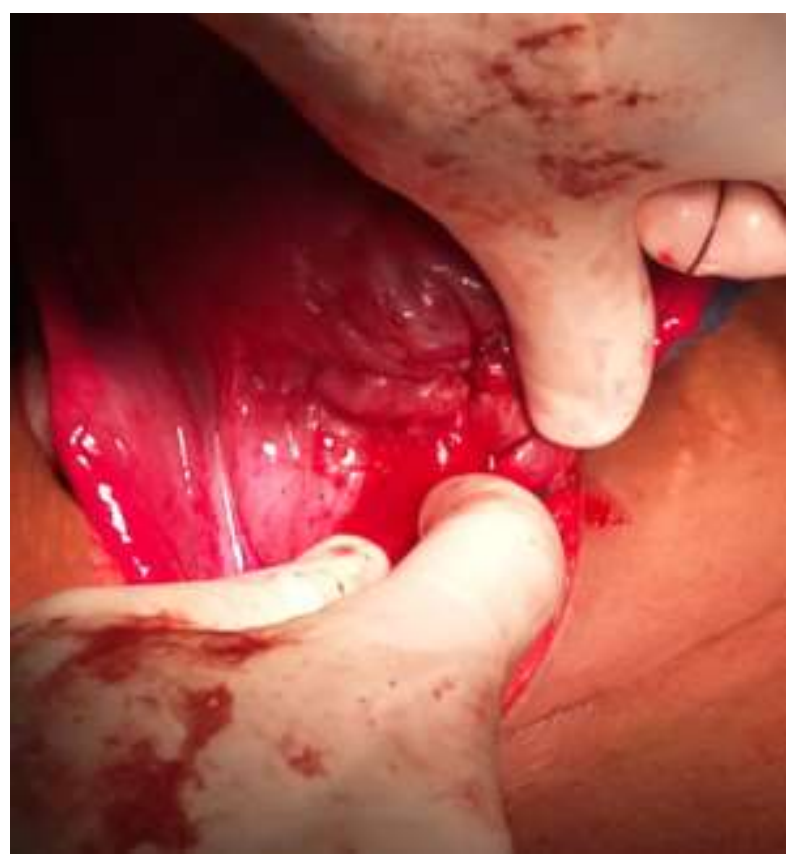

Figure 2: Plication sutures taken in the lower uterine segment. 


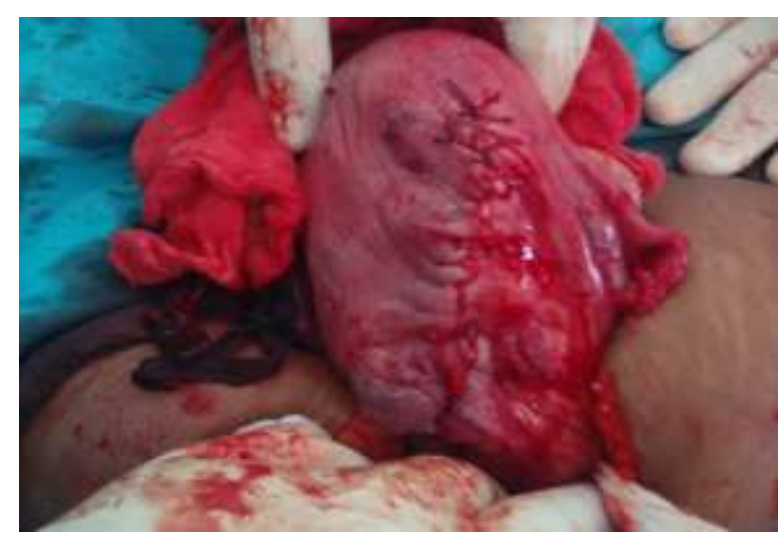

Figure 3: uterus after successful compression sutures, closure of upper segment incision and adequate haemostasis.

\section{DISCUSSION}

Placenta accreta is a serious cause for postpartum hemorrhage. Its incidence is increasing worldwide secondary to increase in rate of caesarian section deliveries. Many authors have proposed different methods for control of hemorrhage in these cases. Blynch and Hayman techniques are more successful in treatment of hemorrhage from upper uterine segment. ${ }^{4,5}$

Rabbo A presented stepwise de-vascularization, it entails unilateral then bilateral uterine artery ligation, followed by unilateral ovarian artery ligation. ${ }^{6}$ It act locally by decreasing pulse pressure at the placental bed and allowing time for clotting factors to achieve hemostasis. Yildiz et al presented a case series with internal iliac artery ligation for control of postpartum hemorrhage, yet it holds the need for obstetricians with good experience of retroperitoneal dissection and entails the risk of iliac vein or external iliac artery injury. ${ }^{7}$ Winograd et al and Soro et al presented internal iliac artery catheterization and embolization for pelvic devascularization, yet it still holds the need for trained interventional radiologist, with the use of expensive machinery.

Estimated blood loss was roughly by weighing of laparotomy pads before and after soiling and amount in suction apparatus.

Table 1: Patient data.

\begin{tabular}{|c|c|c|c|c|c|c|}
\hline $\begin{array}{l}\text { Age } \\
\text { (yr) }\end{array}$ & $\begin{array}{l}\text { Number of } \\
\text { previous } \\
\text { cesarean } \\
\text { sections }\end{array}$ & $\begin{array}{l}\text { Gestational } \\
\text { age at } \\
\text { delivery }\end{array}$ & $\begin{array}{l}\text { Estimated } \\
\text { blood loss } \\
\text { in } \mathrm{ml}\end{array}$ & $\begin{array}{l}\text { Operative } \\
\text { time in } \\
\text { minutes }\end{array}$ & $\begin{array}{l}\text { Amount of transfused blood } \\
\text { products }\end{array}$ & Management \\
\hline 26 & 2 & $37 \mathrm{w} 1 \mathrm{~d}$ & 1800 & 50 & 1 litre blood, $400 \mathrm{ml} \mathrm{FFP}$ & Conservative \\
\hline 31 & 3 & $36 \mathrm{w} 4 \mathrm{~d}$ & 2000 & 55 & 1.51 blood, $400 \mathrm{ml} \mathrm{FFP}$ & Conservative \\
\hline 28 & 2 & $36 \mathrm{w} 5 \mathrm{~d}$ & 2200 & 50 & 1.5 litre, $400 \mathrm{ml}$ FFP & Conservative \\
\hline 39 & 4 & $36 \mathrm{w} 6 \mathrm{~d}$ & 3500 & 75 & 2.51 blood, $600 \mathrm{ml} \mathrm{FFP}$ & Hysterectomy \\
\hline 32 & 2 & $37 \mathrm{w} 1 \mathrm{~d}$ & 1800 & 55 & 1 litre blood, $400 \mathrm{ml} \mathrm{FFP}$ & Conservative \\
\hline 24 & 3 & $37 \mathrm{w} 4 \mathrm{~d}$ & 3800 & 80 & 3 litre blood, $600 \mathrm{ml} \mathrm{FFP}$ & Hysterectomy \\
\hline 40 & 3 & $37 \mathrm{w} 2 \mathrm{~d}$ & 3000 & 70 & 2 litre blood, $600 \mathrm{ml} \mathrm{FFP}$ & Hysterectomy \\
\hline 33 & 2 & $37 \mathrm{w} 2 \mathrm{~d}$ & 1600 & 60 & 1 litre, 400 ml FFP & Conservative \\
\hline 35 & 3 & $37 \mathrm{w} 4 \mathrm{~d}$ & 2500 & 55 & 1.5 litre blood, $400 \mathrm{ml} \mathrm{FFP}$ & Conservative \\
\hline 40 & 4 & $36 \mathrm{w} 1 \mathrm{~d}$ & 3000 & 75 & 2 litre blood, $600 \mathrm{ml} \mathrm{FFP}$ & Hysterectomy \\
\hline 26 & 1 & $36 \mathrm{w} 3 \mathrm{~d}$ & 1500 & 50 & 1 litre blood, 300 FFP & Conservative \\
\hline 29 & 2 & $36 \mathrm{w} 4 \mathrm{~d}$ & 2700 & 80 & 2 litre blood, $600 \mathrm{ml} \mathrm{FFP}$ & Conservative \\
\hline 31 & 2 & $37 \mathrm{w} 1 \mathrm{~d}$ & 2000 & 55 & 1 litre blood, $400 \mathrm{ml} \mathrm{FFP}$ & Conservative \\
\hline 30 & 2 & $36 \mathrm{w} 1 \mathrm{~d}$ & 2000 & 55 & 1 litre blood, $400 \mathrm{ml} \mathrm{FFP}$ & Conservative \\
\hline 29 & 3 & $37 \mathrm{w} 3 \mathrm{~d}$ & 2400 & 55 & 2 litre blood, $600 \mathrm{ml} \mathrm{FFP}$ & Conservative \\
\hline 34 & 4 & $36 \mathrm{w} 5 \mathrm{~d}$ & 3400 & 80 & 2.5 litre blood, $600 \mathrm{ml} \mathrm{FFP}$ & Hysterectomy \\
\hline 33 & 2 & $36 \mathrm{w} 2 \mathrm{~d}$ & 2300 & 60 & 2 litre blood, $500 \mathrm{ml} \mathrm{FFP}$ & Conservative \\
\hline 31 & 2 & $37 \mathrm{w} 4 \mathrm{~d}$ & 2300 & 60 & 2 litre blood, $400 \mathrm{ml} \mathrm{FFP}$ & Conservative \\
\hline 34 & 2 & $36 \mathrm{w} 4 \mathrm{~d}$ & 2300 & 90 & 1 litre blood, $500 \mathrm{ml} \mathrm{FFP}$ & Conservative \\
\hline 31 & 2 & $37 \mathrm{w} 1 \mathrm{~d}$ & 1900 & 55 & 1.5 litre of blood, $400 \mathrm{ml} \mathrm{FFP}$ & Conservative \\
\hline 33 & 3 & $37 \mathrm{w} 0 \mathrm{~d}$ & 2500 & 60 & 2 litre of blood, $600 \mathrm{ml} \mathrm{FFP}$ & Conservative \\
\hline 39 & 3 & $36 \mathrm{w} 5 \mathrm{~d}$ & 3500 & 70 & 2.5 litre of blood, $600 \mathrm{ml} \mathrm{FFP}$ & Hysterectomy \\
\hline 30 & 1 & $37 \mathrm{w} 2 \mathrm{~d}$ & 1800 & 50 & 1 litre blood, $400 \mathrm{ml} \mathrm{FFP}$ & Conservative \\
\hline 38 & 2 & $37 \mathrm{w} 4 \mathrm{~d}$ & 2000 & 60 & 1.5 litre of blood, $500 \mathrm{ml} \mathrm{FFP}$ & Conservative \\
\hline 36 & 3 & $37 \mathrm{w} 3 \mathrm{~d}$ & 2200 & 80 & 1.5 litre of blood, $400 \mathrm{ml} \mathrm{FFP}$ & Conservative \\
\hline
\end{tabular}


The use of balloon compression, as Bakri Balloon, has also been proposed in cases of placenta accreta. ${ }^{10}$

This study presented a multistep approach for fertility preservation in cases with placenta accreta. We combined methods from different studies to achieve hemostasis. Right para median abdominal incision gives access to the upper uterine segment to avoid delivery of the fetus through torn placenta by a lower segment incision. Dissection of the urinary bladder downwards allowed access to lower uterine segement before fetal extraction. This reduced the time needed for lower segement plication after fetal extraction. Bilateral uterine artery ligation after fetal extraction and before placenta removal reduced the pulse pressure in the placenta bed, helping in reduction of blood loss and achieving hemostasis after placental removal. Plication of lower segment and compression sutures from the anterior to posterior walls achieved hemostasis in 19 out of 25 cases ( $76 \%$ success rate) without the need for hysterectomy. Three patients had urinary bladder injury, which necessitated insertion of Foley's catheter for one week post-operative. No mortalities occurred in our study. None of the cases reached the stage of massive blood transfusion (defined as 8 or more units of blood within 24 hours after delivery). ${ }^{11}$ Compared to other case series were cases of placenta accrete had $100 \%$ caesarian hysterectomy, our study presents a fairly successful method for conservative treatment. ${ }^{11}$ Iatrogenic bladder injury occurred in $30 \%$ of conservative cases that was repaired by the gynecologist using double layer closure with $3 / 0$ vicryl suture.

Reduction in blood loss with our multistep approach resulted in significant reduction in blood loss, similar to that with the use of internal iliac balloon occlusion reported by Li et al, without the high cost and necessary skill for these arterial catheter insertion. ${ }^{12}$ In a smaller series of seven patients, Shazly et al reported the use of compression sutures in cases with failed uterine artery ligation to achieve hemostasis. ${ }^{13}$

Chandraharan et al described the 'triple- $\mathrm{P}$ ' procedure entailing delivery of the fetus via transverse uterine incision above the upper border of the placenta; pelvic de-vascularization; and placental non-separation with myometrial excision and reconstruction of the uterine wall. $^{14}$ Kaplanoğlu described the 'uterine sandwich method' combining B-lynch sutures with intrauterine gauze tamponade for control of hemorrhage in cases with one case with placenta accreta. ${ }^{15}$ Mechsner et al applied B-lynch compression with uterine artery embolization and recombinant factor VII for the treatment of one case of placenta accreta. ${ }^{16}$

As mentioned by Cunningham et al, risk of recurrent placenta accreta is $20 \%$ in subsequent pregnancies, so cases successful managed conservatively were carefully counseled about that risk. ${ }^{17}$

\section{CONCLUSION}

Conservative management of placenta accrete can be successfully performed in young age females desiring fertility using plication of the lower uterine segment and multiple transverse compression sutures.

\section{Funding: No funding sources}

Conflict of interest: None declared

Ethical approval: The study was approved by the Institutional Ethics Committee

\section{REFERENCES}

1. Palova E, Redecha M, Malova A, Hammerova L, Kosibova Z. Placenta accreta as a cause of peripartum hysterectomy. Bratisl Lek Listy. 2016;117(4):212-6.

2. El-Agwany AS. Bilateral Absence of Common Iliac Artery: Abnormal anatomical variation of the Internal Iliac Artery during Ligation in Conservative Surgical Management of Placenta Previa Accreta Indian Journal of Gynecologic Oncology. 2016;14(2):1-6.

3. D'Antonio F, Iacovella C, Bhide A. Prenatal identification of invasive placentation using ultrasound: systematic review and meta-analysis. Ultrasound Obstet Gynecol. 2013;42(5):509-17.

4. El-Hamamy E, Wright A, B-Lynch C. The B-Lynch suture technique for postpartum haemorrhage: a decade of experience and outcome. J Obstet Gynaecol. 2009;29(4):278-83.

5. Ghezzi F, Cromi A, Uccella S, Raio L, Bolis P, Surbek D. The hayman technique: a simple method to treat postpartum haemorrhage. BJOG. 2007;114(3):362-5.

6. AbdRabbo SA. Stepwise uterine devascularization: a novel technique for management of uncontrolled postpartum hemorrhage with preservation of the uterus. Am J Obstet Gynecol. 1994;171(3):694-700.

7. Yildiz C, Akkar OB, Karakuş S, Cetin A, Yanik A. Hypogastric artery ligation for obstetrical hemorrhage: clinical experience in a tertiary care center. Turk J Med Sci. 2015;45(6):1312-6.

8. Winograd RH. Uterine artery embolization for postpartum hemorrhage. Best Pract Res Clin Obstet Gynaecol. 2008;22(6):1119-32.

9. Soro MP, Denys A, de Rham M, Baud D. Short and long term adverse outcomes after arterial embolisation for the treatment of postpartum haemorrhage: a systematic review. Eur Radiol. 2016: PMID: 27229338.

10. Akdemir N, Cevrioğlu AS, Özden S, Gündüz Y, Ilhan G. Successful treatment of placenta percreta through a combinatorial treatment involving a Bakri Balloon and Methotrexate a case report. Ginekol Pol. 2015;86(8):631-4.

11. Chester J, Sidhu P, Sharma S, Israfil-Bayli F. Emergency peripartum hysterectomies at a District 
General Hospital in United Kingdom: 10-year review of practice. Scientifica. 2016;2016:9875343.

12. Li GT, Li XF, Wu B, Li G. Longitudinal parallel compression suture to control postpartum hemorrhage due to placenta previa and accreta. Taiwan J Obstet Gynecol. 2016;55(2):193-7.

13. Shazly SA, Badee AY, Ali MK. The use of multiple compressions suturing as a novel procedure to preserve fertility in patients with placenta accreta: case series. Aust N Z J Obstet Gynaecol. 2012;52(4):395-9.

14. Chandraharan E, Rao S, Belli AM, Arulkumaran S The triple-P procedure as a conservative surgical alternative to peripartum hysterectomy for placenta percreta. Int J Gynaecol Obstet. 2012;117(2):191-4.

15. Kaplanoğlu M. The Uterine Sandwich Method for Placenta Previa Accreta in Mullerian Anomaly:
Combining the B-Lynch Compression Suture and an Intrauterine Gauze Tampon. Case Reports in Obstetrics and Gynecology. 2013;236069.

16. Mechsner S, Baessler K, Brunne B, Albrecht T, Hopp H, Dudenhausen JW. Using recombinant activated factor VII, B-lynch compression, and reversible embolization of the uterine arteries for treatment of severe conservatively intractable postpartum hemorrhage: new method for management of massive hemorrhage in cases of placenta increta. Fertil Steril. 2008;90(5):2012.e1-5.

17. Cunningham KM, Anwar A, Lindow SW. The recurrence risk of placenta accreta following uterine conserving management. J Neonatal Perinatal Med. 2016;8(4):293-6.

Cite this article as: El-Agwany AS, Abdeldayem TM. Multistep approach for control of postpartum hemorrhage in placenta accreta: a novel scheme in a tertiary referral center. Int J Reprod Contracept Obstet Gynecol 2016;5:2799-2803. 